\title{
Are we at a turning point in the evolution of gastronomy?
}

Paris: An exemplary case

Christian Barrère, Quentin Bonnard and Véronique Chossat ${ }^{*}$

\begin{abstract}
Over the past few years, the landscape of top class gastronomy has empirically changed: some celebrity chefs are returning their hard-won awards to instead provide low-cost food whilst others work tirelessly to gain access to the inner circle of international top-class restaurants. Things are changing, but the direction is unclear. To analyse the situation, we took the case of French Parisian gastronomy - because it has been the main model for world gastronomy. Our study of it focuses on the Michelin Guide selection, covering the sixty-year period 1950-2012. We then applied MCA (Multiple Correspondence Analysis) to establish the profiles of the Parisian restaurants and to find out whether these profiles have evolved. This paper shows that a turning point has clearly been reached, and that gastronomic pluralism is on the rise - to the detriment of the hegemony of elitist gastronomy.
\end{abstract}

JEL: Z10

Keywords: gastronomy; luxury industries; segmentation; MCA

Université de Reims Champagne-Ardenne, Laboratoire Regards, 57 bis rue Pierre Taittinger, 51096 Reims Cedex, France.

E-mail: christian.barrere@gmail.com - quentin.bonnard@univ-reims.fr - veronique.chossat@univ-reims.fr Corresponding author: Christian Barrère, 7 rue de l'Onglet, 95300 Ennery, France. 


\section{Are we at a turning point in the evolution of gastronomy? \\ Paris: An exemplary case}

\section{Introduction}

Some might consider the study of gastronomy to be a bit of a frivolous subject. Nevertheless, it is something that now concerns many people. The demand for gastronomic services is growing fast, and gastronomy has become a topic for the masses. Famous chefs make magazine headlines (Ferran Adrià, Ishida Katsumi, Gordon Ramsay, etc.); TV programmes show luxury restaurants, and give chefs' recipes; sometimes whole channels are exclusively dedicated to gastronomy. These gastronomic information channels are now aimed squarely at millions of potential consumers, rather than remaining restricted to the elite, stimulating mass demand for gastronomic information and debates.

A great many surprising changes have recently taken place in this area. On the one hand, the strategies of chefs and managers are prize and star-oriented - mainly targeting Guide Michelin (now Red Guide) stars. Specialists agree on the idea that winning a Michelin star increases receipts by up to approximately thirty per cent. On the other hand, although some very expensive establishments serving a very sophisticated cuisine make a lot of money, and export their restaurants all over the world (Joël Robuchon owns 23 restaurants with a total of 27 Michelin stars; Paul Bocuse (3-star chef since 1965) has 19; Gordon Ramsay has 27) and build profitable groups (under the Ducasse group name, Alain Ducasse has 24 restaurants throughout the world, and a total of 19 Michelin stars), others give back their gastronomic awards, tending to seek out the roots of gastronomy. This is true of Alain Senderens - owner of Lucas Carton, one of the most elegant Parisian restaurants in the seventies and eighties who gave back his three Michelin stars in 2005 to adapt low-cost principles to a luxury profession. 
How should these divergent changes be interpreted? Is this a turning point in the evolution of gastronomy? Is it a crisis of the traditional (and still dominant) model of gastronomy we can define as an elitist model? Can we speak of the "democratisation" of gastronomy? Of gastronomic pluralism? Since Paris is traditionally considered to be the historical founder and capital of elitist gastronomy, it is interesting to carefully consider the changes occurring in Parisian gastronomy. The aim of this paper is therefore to propose an assessment of the changes, through the study of French Parisian gastronomy over a significant sixty-year period. In order to do so, the next section is dedicated to a statistical analysis of the empirical changes, which reveals a turning point in the nineties. Then, in the third section, we examine this evolution of French gastronomy using MCA (Multiple Correspondence Analysis) to specify the evolution of the segmentation of the Parisian gastronomic market. MCA allows us to compare segmentation of the Parisian gastronomic market in 1960 with that of 2012, and then to make sense of mutations in the gastronomic market. Section 4 offers some conclusions and relates changes in both gastronomy and the luxury domain.

\section{Sixty years of Parisian gastronomy and a turning point}

The Guide Rouge Michelin is the longest-established and most influential of French guidebooks. It selects and rates hotels and restaurants using pictograms (respectively Pavilions and Forks and Spoons $(F \& S)$ to assess the comfort of the setting, and gives awards - such as Stars, for cooking). There are four star levels (0 to 3) and six comfort levels ("simple comfort" (no F\&S), "quite comfortable" (1 F\&S) "comfortable" (2 F\&S), "very comfortable" (3 F\&S), "top class comfort" (4 F\&S) and "luxury" (5 F\&S).

\subsection{Market Extension}


For the Paris case, 193 restaurants were selected in 1934, 324 in 1950, 359 in 1960, 354 in 1970, 373 in 1980, 438 in 1990, 513 in 2000, 493 in 2010 and 506 in 2012. Between $1934^{1}$ and 2012 the increase exceeds $162 \%$, and between 1950 and 2012 it goes beyond $56 \%$. There are numerous explanations for this. Objectively, at the beginning of the 1930s, Paris counted fewer gastronomic establishments than it does now. The increase in the number of selected establishments tracks the development of the catering market, as well as, more generally, the increasing demand. Since the end of the Second World War, the French population has increased significantly, from 40 to 65 million. Living standards have improved considerably ${ }^{2}$. And tourism has also evolved; for instance, in Paris the number of visitors to the Eiffel Tower multiplied by 6.9 between 1950 and 2012. The expansion of catering supply follows that of potential demand. So the market is growing - in spite of very significant growth in relative prices $^{3}$ according to either level of comfort or quality of cooking.

\footnotetext{
${ }^{1} 1934$ represents the beginning of the evaluation of the quality of cooking through the Michelin stars. Prior to this date, the Michelin guidebook was just a restaurants and hotels yearbook covering France, and was mainly used by sales representatives.

${ }^{2}$ For instance, French GDP in 1950 was $€ 15$ billion, compared with $€ 1,440$ billion in 2000 (in constant euros, 2011 base). French GDP in 2011 (according to the International Monetary Fund) is $€ 2,239$ billion. In the France of 2007, average gross wage per capita was about $€ 32,200$ whereas it was only $€ 7,600$ in 1950 (in constant data). Source: G. Bouvier and C. Pilarski (2008), Soixante ans d'économie française: des mutations structurelles profondes. INSEE Première, $\mathrm{n}^{\circ} 1201$ (July).

${ }^{3}$ Michelin provides information on the price of a meal in selected restaurants: prices for the fixed-price menu, or à la carte, and for each, one minimum and one maximum price. In constant euro (2011 base), the average price of a low-end menu in the restaurants selected by the Michelin Guide in Ile de France (the Paris area) was 13.3 in 1950, 32.8 in 2000 and 45.8 in 2012; for the high-end menu we have respectively 18.4, 47.6 and 65.5; for the low-end à la carte 20.4, 49.5 and 53.7; for the high-end à la carte 24, 69.7 and 86.6.
} 


\subsection{Market Segmentation}

\section{Prices}

Figure 1 shows that price evolution is specific to the level of comfort, especially from $1980 . \AA$ la carte prices of the top categories ( 4 and $5 \mathrm{~F} \& \mathrm{~S}$ ) have stronger growth. Prices reach very high levels. From the 1980s it becomes possible to connect together the evolution of setting and prices.

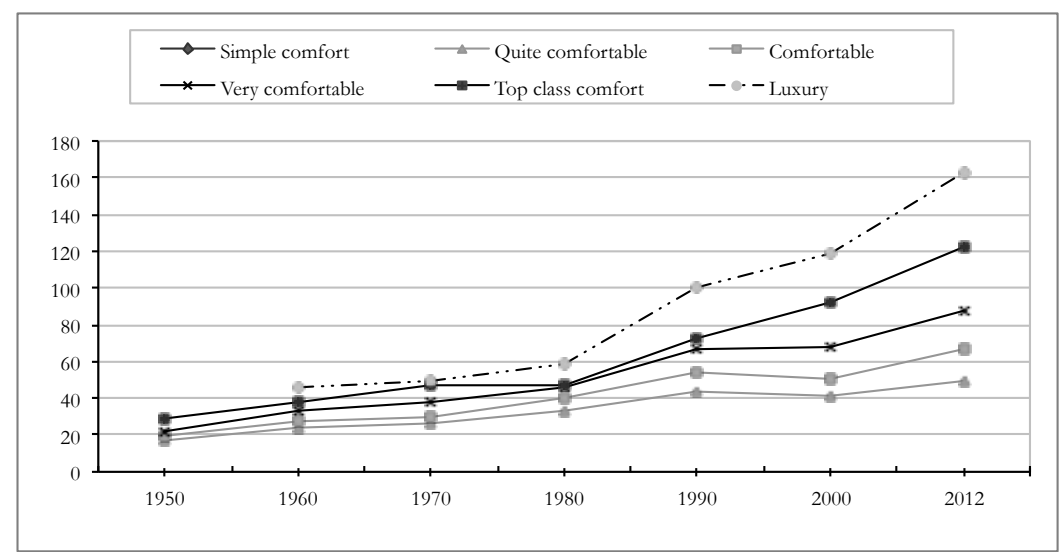

Figure 1. À la carte price and setting ${ }^{4}$

Figure 2 confirms this movement. The relative increase in prices is stronger for the top categories ( 2 and 3 stars). This price evolution can be interpreted by identifying two main and distinct segments: an elitist niche (4 and 5 F\&S including 2 and 3 star restaurants) and mass consumption gastronomic restaurants, including the 2 and 3 F\&S restaurants (and even onestar establishments) and the $1 \mathrm{~F} \& \mathrm{~S}$ and no $\mathrm{F} \& \mathrm{~S}$ ones.

\footnotetext{
${ }^{4}$ The evolution of menu prices and setting is a close match.
} 


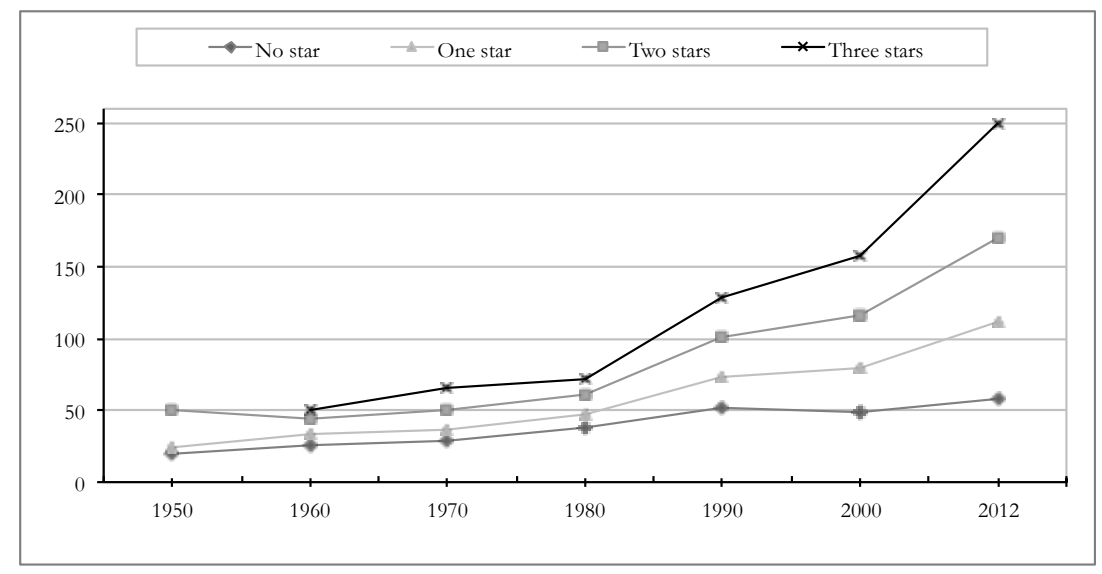

Figure 2. À la carte price and awards

\section{Setting}

Table 1 shows the average setting of the selected Parisian establishments according to the award Michelin gives them. On the one hand, we can see that restaurants had 2.4 F\&S in 1960, 2.16 in 2000 and 1.89 in 2012. More precisely, the setting of the selected establishments remained stable, rising just a little in the 1960 to 1990 period. But the situation changes after 1990, as the average setting fell, to decrease further in 2012 . On the other hand, we can observe that the setting of "starred" restaurants is always the same over time. The more stars selected establishments have, the more F\&S they have, too. So, according to setting, our findings are the same, with strong segmentation across two components: the first being the elitist segment, which implies stars and a high level of comfort and the second being the mass or democratic segment, which implies a minimum level of comfort and which makes up the lion's share of the Michelin Paris selection.

\begin{tabular}{|l|ccccccc|}
\hline & 1960 & 1970 & 1980 & 1990 & 2000 & 2010 & 2012 \\
\hline Average Setting (AS) & 2.4 & 2.36 & 2.43 & 2.5 & 2.16 & 1.94 & 1.89 \\
AS \& 0 Star & 2.31 & 2.26 & 2.37 & 2.33 & 1.92 & 1.71 & 1.71 \\
AS \& 1 Star & 2.25 & 2.23 & 2.35 & 2.79 & 3.16 & 2.41 & 2.46 \\
AS \& 2 Stars & 3.59 & 3.67 & 3.64 & 3.94 & 4.11 & 3.62 & 3.29 \\
AS \& 3 Stars & 4.5 & 4.6 & 4.17 & 4.6 & 4.43 & 4.3 & 4.3 \\
AS \& Bib & - & - & - & - & 1.31 & 1.17 & 1.13 \\
\hline
\end{tabular}

Table 1. Average setting of establishments and awards 
Within the population of Michelin selected establishments, the selection boundaries have evolved. More and more "standard comfort level" restaurants have sprung up since the 2000s, in comparison with the "highest comfort level" ones. Table 2 shows this structure.

\begin{tabular}{|c|ccccccccc|}
\hline & 1934 & 1950 & 1960 & 1970 & 1980 & 1990 & 2000 & 2010 & 2012 \\
\hline $0+1 \mathrm{~F} \& S$ & $23.83 \%$ & $22.84 \%$ & $20.33 \%$ & $22.32 \%$ & $20.64 \%$ & $17.12 \%$ & $35.48 \%$ & $48.07 \%$ & $49.60 \%$ \\
$2+3 \mathrm{~F} \& S$ & $60.10 \%$ & $59.26 \%$ & $64.35 \%$ & $61.30 \%$ & $61.13 \%$ & $61.42 \%$ & $48.15 \%$ & $39.35 \%$ & $40.51 \%$ \\
$4+5 \mathrm{~F} \& S$ & $16.06 \%$ & $17.90 \%$ & $15.32 \%$ & $16.38 \%$ & $18.23 \%$ & $21.46 \%$ & $16.37 \%$ & $12.58 \%$ & $9.88 \%$ \\
\hline
\end{tabular}

Table 2. Segmentation through the setting of establishments

To be clearer in our consideration of comfort levels, we can group the six categories of the Michelin ranking into three: (1) $0 \mathrm{~F} \& S^{5}$ and $1 \mathrm{~F} \& S$, (2) $2 \mathrm{~F} \& S$ and $3 \mathrm{~F} \& S$, (3) $4 \mathrm{~F} \& S$ and 5 $\mathrm{F} \& \mathrm{~S}^{6}$. The top segment (i.e. $4 \mathrm{~F} \& \mathrm{~S}$ and $5 \mathrm{~F} \& \mathrm{~S}$ ) is the gastronomic luxury showcase (very high prices, celebrity chefs...).

In 2012, the two first segments $(0+1 \mathrm{~F} \& S$ and $2+3 \mathrm{~F} \& S)$ represent $90 \%$ of the selected Parisian establishments, even more than they did at the beginning (83\% in 1950). Moreover, their respective weights changed during the period. In $19500+1 \mathrm{~F} \& \mathrm{~S}$ represented only $23 \%$ and their share decreased until the nineties (17\% in 1990) whereas the weight of the $2+3 \mathrm{~F} \& S$ segment was stable at about $60 \%$. This means that the bottom segment lost out to the top one, the elitist niche. But things evolved significantly between 1990 and 2012, with an increase of more than $142 \%$ in $1 \mathrm{~F} \& \mathrm{~S}$, whereas the global increase was about $17 \%$; then, from $23 \%$ at the beginning and $17 \%$ in 1990 , the bottom category now reached $49.6 \%$. This growth comes at

\footnotetext{
${ }^{5} 0$ F\&S is not represented in Paris, yet it is used in other French regions and in other issues of the Michelin guidebook, such as New York City, for example.

${ }^{6}$ These three new categories are relatively homogeneous. There are minor differences between 0 and $1 \mathrm{~F} \& \mathrm{~S}$, between 2 and 3, and between 4 and 5 , as is attested to by the fact that some restaurants frequently evolve within our new categories (for instance from 2, to 3 one year, and after some years they return to 2) but rarely between our three categories. Moreover the criteria used for the ranking are close within our three categories (there are few differences between a 2 and $3 \mathrm{~F} \& \mathrm{~S}$ ).
} 
the expense of other categories, the segment $2+3 \mathrm{~F} \& \mathrm{~S}$ (from $61.4 \%$ in 1990 to $40.5 \%$ in 2012) and, mainly, the elitist niche, which grew from $17.9 \%$ in 1950 to $21.5 \%$ in 1990 - only to strongly decline to $9.9 \%$ in 2012 !

This evolution can be analysed as a reorganisation of segments within the population of the selected Parisian establishments. Today, the new gastronomic establishments are mainly neither elitist not cheapest restaurants (in spite of the media impact of the new Parisian palaces) but more standard ones. Similarly, at the end of the 1990s, the "Bib Gourmand" pictogram ${ }^{7}$ was launched. This in fact derives from the pre-existing " $R$ " (meaning "simple meal") the meaning of which was quite similar. However, whereas in the 1950s and 1960s there were no Parisian establishments with "R" (and there were still only 3 in $1990^{8}$ ), Table 3 shows the extreme rise in this kind of "democratic" gastronomy since 2000.

\begin{tabular}{|l|rrrrrrrr|}
\hline & 1950 & 1960 & 1970 & 1980 & 1990 & 2000 & 2010 & 2012 \\
\hline "Starred" & 78 & 97 & 92 & 92 & 94 & 76 & 64 & 77 \\
"Bibed" & - & - & - & - & - & 36 & 65 & 70 \\
"Awarded" & 78 & 97 & 92 & 92 & 94 & 112 & 129 & 147 \\
"Selected" & 324 & 359 & 354 & 373 & 438 & 513 & 493 & 506 \\
\% Bib in the selection & & & & & & $7.68 \%$ & $13.18 \%$ & $13.83 \%$ \\
\hline
\end{tabular}

Table 3. Michelin's Stars and Bibs Gourmands

The place of this population is increasing in the selection, from $7.7 \%$ of the Parisian selected establishments to $13.8 \%$ in 2012 . It is also growing in the awarded restaurants, that is to say in the gastronomic restaurants offering a high quality cuisine. We can see that the number of "starred" restaurants has decreased from 1950 to 2012 but in the same time those restaurants

\footnotetext{
${ }^{7}$ In reference to the Michelin Bibendum, which has been the Michelin mascot since the company's very beginnings.

${ }^{8}$ The Ile-de-France region had 13 "R" establishments in 1957 and in 1968, for example but the city of Paris had none.
} 
having a Bib Gourmand have risen from 36 in 2000 to 70 in 2012. They are now more numerous in the selection than the "starred" ones".

This reveals a general trend in the diverse issues of the Michelin Red Guide. In London in 2012, Bibs Gourmands represent almost $10 \%$ of the selected establishments (there are 45 Bibs and 55 Michelin-starred restaurants out of 500 selected); in Lyon they represent $14.29 \%$ (10 Bibs and 10 Michelin-starred restaurants out of 70 selected); in New York, $14.16 \%$ (114 Bibs and 62 Michelin-starred restaurants out of 805 selected). This is a new award linked to the necessity of enlightening not just the top of the hierarchy but also a growing proportion of chefs who are responding to increasing potential demand for less sophistication and flashy luxury. This movement expresses an adaptation of the Michelin philosophy to changes occurring in both supply and demand. Numerous top chefs have deserted the luxury and middle comfort segments to offer more "standard" food amenities. Certain renowned examples come to mind, such as Alain Senderens (Lucas Carton, Paris), Olivier Rollinger (Les Maisons de Bricourt, Cancale), Philippe Gaertner (Aux Armes de France, Ammerschwihr), and Hervé Paulus (Hostellerie Paulus, Landser). This movement, which began in France, has spilled out of French boundaries to touch famous Italian chefs in particular, such as Ezio Santin (Antica Osteria del Ponte, Cassinetta di Lugagnano), and Gualtiero Marchesi (Gualtiero Marchesi Restaurant at L'Albereta, Erbusco) each of whom had earned three Michelin stars.

We have seen that the field of gastronomy in Paris has become broader - in terms of the number of restaurants - over time. We have then observed that the weighting of its segments (elitist niche -4 and 5 F\&S including 2 and 3 stars, intermediate segment -2 and 3 F\&S including one star establishments- and lowest segment -1 F\&S and no F\&S) has changed. The

\footnotetext{
9 As the number of "awarded" establishments have increased $88.46 \%$ over our study period, it is not a substitution movement. Bib restaurants join starred restaurants, rather than replacing them.
} 
1990s seem to constitute a turning point between a trend of increasingly elitist gastronomy and a new trend of enlarging the field of legitimated gastronomy through the use of less sophisticated cuisine and settings. Nevertheless, this analysis is based on the empirical categories of the Red Michelin Guide: six categories of comfort, three levels of stars and the Bibs. In order to be precise and to consolidate this analysis, we must now observe whether coherent restaurant profiles, allowing us to establish a scientific classification, can be defined. Thus we might compare the profiles of the Parisian restaurants at two different times and check whether these profiles have changed. The next section presents a data analysis based on three Multiple Correspondence Analyses (MCA).

\section{Evolution in segmentation: from old to new}

\subsection{Empirical specification and data}

The dataset used covers gastronomic restaurants ${ }^{10}$ listed in the Michelin Guide in $1960^{11}$, 2010 and 2012 for the different districts of Paris (the choice of two different years (2010 and 2012) for the recent period allows us to check that our results are not related to a particular year, and that evolution is proven). Concerning the Parisian fine dining restaurants in 1960, our database gives information on:

- Quality of comfort is translated into a number of Forks and Spoons (F\&S) from 5 (high) to 0 (low). Their level of comfort can be simple comfort (0 F\&S), quite comfortable (1

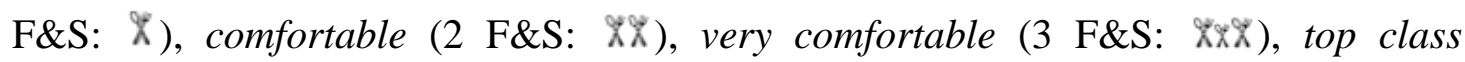
comfortable (4 F\&S: $18 \times 8 \%)$ or luxury in the traditional style (5 F\&S: $8 \times 8 \times 8 \%)$.

\footnotetext{
${ }^{10}$ The Michelin Guide identifies two types of establishments: restaurants and hotels with public restaurants. Here, we are dealing only with gastronomic services and not hotels; because there are too few examples of the second category, the statistical analysis is unbalanced. Moreover, the Parisian gastronomic market depicted by the Michelin guidebook principally comprises restaurants.

${ }^{11}$ The year 1960 is more interesting than the year 1950 because 1950 was too close to the Second World War and its food rationing.
} 
- The most comfortable restaurants are announced by Red F\&S (max). When an establishment gets red $F \& S$ instead of black ones, it means that it is especially pleasant. That is to say, a 4 red F\&S restaurant has a better environment, a more pleasant or luxurious setting than a 4 black F\&S but less than a 5 black F\&S.

- Quality of cuisine ${ }^{12}$ is symbolised by Michelin gastronomic awards. It may be 1 star: $\varepsilon_{3}$ (Very Good Cuisine in its category), 2 stars: $\xi^{3} \varepsilon_{3}$ (Excellent Cuisine, worth a detour), 3

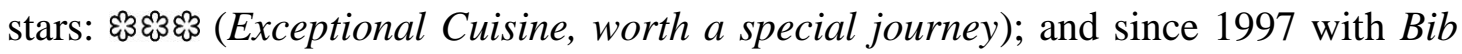
Gourmand: According to Michelin, "The Bib Gourmand category, also known as "Inspectors' Favourites for Good Value", has been embraced by Michelin Guide readers as providing a recession-proof dining solution". These restaurants serve a meal (two courses and a glass of wine or dessert) for $€ 35$ or less.

- Their price is expressed in 4 categories.

We have 4 variables representing 15 modalities for each of the 243 Parisian restaurants ${ }^{13}$ selected in 1960 and the 456 Parisian restaurants selected in 2012. Over time, the Michelin Guide has refined information on selected establishments. Consequently, in 2010, we have the same indications as in 1960 , as well as additional information such as:

- The type of cooking which can be "Au goût du jour”, Classical, Creative, Traditional, Regional, or Foreign

- The reputation of the Chef

- Whether the restaurant offers a Notable wine list

- Whether the restaurant offers Valet Parking.

- Whether the restaurant offers a sub-€30 and sub-€19 fixed-price menus

\footnotetext{
${ }^{12}$ More precisely, obtaining and maintaining a Michelin star (or stars) is based on five criteria: "the quality of products, the mastery of flavour and cooking, the personality of the cuisine, the value for the money, the consistency between visits" (www.michelinguide.com/ratings.html).

${ }^{13}$ Paris in fact had 279 selected restaurants in 1960. However, 36 of these have not disclosed the price of their bills, and therefore had to be excluded from our dataset.
} 
We thus have 16 variables, representing 59 modalities for each of the 425 Parisian restaurants selected in 2010.

\begin{tabular}{l|lrc}
\hline Variable & Definition & Mean & Std. Dev \\
\hline COMFORT(i) & Quality of the setting of the restaurant i measured by the Michelin F\&S & 2.247 & 1.002 \\
RED.F\&S(i) & Greater comfort of the restaurant i =1, other $=0$ & 1.016 & 0.128 \\
CUISINE(i) & Quality of cooking at the restaurant i measured by the Michelin Awards & 1.498 & 0.712 \\
PRICE(i) & Price of a meal in the restaurant i, without drink & 2.794 & 0.871 \\
\hline
\end{tabular}

Table 5. Definitions and descriptive statistics of the variables (Paris 1960)

\begin{tabular}{l|lcc}
\hline Variable & Definition & Mean & Std. Dev \\
\hline COMFORT(i) & Quality of the setting of the restaurant i measured by the Michelin F\&S & 1.691 & 0.948 \\
RED.F\&S(i) & Greater comfort of the restaurant i =1, other =0 & 1.116 & 0.320 \\
CUISINE(i) & Quality of cooking at the restaurant i measured by the Michelin Awards & 1.572 & 0.975 \\
PRICE(i) & Price of a meal in the restaurant i, without drink & 1.636 & 0.853 \\
\hline
\end{tabular}

Table 6. Definitions and descriptive statistics of the variables (Paris 2012)

\begin{tabular}{|c|c|c|c|}
\hline Variable & Definition & Mean & Std. Dev \\
\hline $\operatorname{COMFORT(i)}$ & Quality of the setting of the restaurant i measured by the Michelin F\&S & 1.664 & 0.932 \\
\hline RED.F\&S(i) & More pleasant comfort of the restaurant $\mathrm{i}=1$, other $=0$ & 0.068 & 0.252 \\
\hline CUISINE(i) & Quality of cooking at the restaurant i measured by the Michelin Awards & 1.532 & 0.953 \\
\hline PRICE(i) & Price of a meal in the restaurant $i$, without drink & 1.544 & 0.814 \\
\hline LOCALISATION(i) & Location of restaurant $\mathrm{i}$ in one of the 20 Parisian districts & & \\
\hline AGDJ(i) & Restaurant serving "Au goût du jour" cuisine $=1$, other $=0$ & 0.275 & 0.447 \\
\hline CLASSICAL(i) & Restaurant serving French Classical cuisine $=1$, other $=0$ & 0.038 & 0.190 \\
\hline CREATIVE(i) & Restaurant serving Creative cuisine $=1$, other $=0$ & 0.054 & 0.226 \\
\hline TRADITIONAL(i) & Restaurant serving French Traditional cuisine $=1$, other $=0$ & 0.376 & 0.485 \\
\hline REGIONAL(i) & Restaurant serving regional cuisine $=1$, other $=0$ & 0.209 & 0.407 \\
\hline FOREIGN(i) & Restaurant serving foreign cuisine $=1$, other $=0$ & 0.047 & 0.212 \\
\hline
\end{tabular}




\begin{tabular}{|c|c|c|c|}
\hline CHEF(i) & Famous Chef (named in the Michelin Guide) $=1$; other $=0$ & 0.158 & 0.364 \\
\hline WINES(i) & Notable wine list $=1$; other $=0$ & 0.155 & 0.362 \\
\hline $\mathrm{VP}(\mathrm{i})$ & Restaurant proposing a valet parking service $=1$; other $=0$ & 0.245 & 0.430 \\
\hline MENU19(i) & Restaurants offering a sub- $€ 19$ menu $=1$; other $=0$ & 0.068 & 0.252 \\
\hline MENU30(i) & Restaurants offering a sub- $€ 35$ menu $=1$; other $=0$ & 0.320 & 0.466 \\
\hline
\end{tabular}

Table 7. Definitions and descriptive statistics of the variables (Paris 2010)

Our dataset comprises qualitative and multivariate data. With regard to 243 restaurants in 1960, 425 in 2010 and 456 in 2012, our files contain a measurement of the quality of comfort of the establishment divided into 5 classes (1 F\&S, 2 F\&S, 3 F\&S, 4 F\&S, 5 F\&S); an additional measure of quality of comfort divided into 2 classes (Red F\&S, Black F\&S); a measurement of the quality of cooking divided into 5 classes ( 0 star, Bib Gourmand, 1 star, 2 stars, 3 stars); and a measurement of prices charged by selected establishments, also regarded as qualitative because this last - initially quantitative - was transformed into a qualitative variable, divided into 4 classes (sub- $€ 15, € 15-25, € 25-35$, over $€ 35$ for 1960 , in constant euro - 2011 base, and sub- €50, €50-100, €100-150, over $€ 150$ for 2010 and 2012).

Our four variables had initially been studied by a univariate analysis, in order to see, for each one, whether the categories had similar observed frequencies, or whether some were too rare, as well as which number of categories there were for each variable. It was also necessary to study the relations between these variables two by two, which is done classically using the statistics of the Chi-Square with the related test. We realised in particular that our four variables are correlated, have a linear relationship between them (Appendix 1 and Appendix 4). In 2010, the price variable is closely correlated with the Comfort (linear correlation coefficient: 0.74 ) and Cuisine (linear correlation coefficient: 0.64) variables. The Cuisine variable is moderately correlated with the variables Comfort (linear correlation coefficient: 0.56) and Red F\&S (linear correlation coefficient: 0.44 ). The Comfort variable is moderately 
correlated with the Red F\&S variable (linear correlation coefficient: 0.53). In 2012, the Price variable is closely correlated with the Comfort (linear correlation coefficient: 0.74 ) and Cuisine variables (linear correlation coefficient: 0.64). The Cuisine variable is moderately correlated with the Comfort (linear correlation coefficient: 0.53) and Red F\&S variables (linear correlation coefficient: 0.36 ). The Comfort variable is moderately correlated with the Red F\&S variable (linear correlation coefficient: 0.46 ). All of these correlations are positive and significant at $1 \%$ level (bilateral test). We can therefore conduct a Multiple Correspondence Analysis (MCA) on our database.

Multiple Correspondence Analysis is a data analysis technique for nominal or categorical data, used to detect and represent underlying structures in a dataset. It does this by representing data as points in a low-dimensional Euclidean space. MCA is "an extension of Correspondence Analysis (CA) which allows one to analyse the pattern of relationships of several categorical dependent variables" (Abdi and Valentin, 2007: 651). It is applicable to a large set of variables. This method can also be seen as a generalisation of Principal Component Analysis (PCA) where the variables to be analysed are categorical, that is to say qualitative, rather than quantitative as they are in PCA. The principle of this statistical method is to reduce the number of dimensions of a large data set without losing too much information. We can trace the principles of this method to Guttman (1941), as well as to Burt (1950) or Hayashi (1956). Other types of extensions of correspondence analysis have been proposed by Escoffier-Cordier (1965), Benzécri (1973) and Masson (1974), drawing on the work of Horst (1961), Carroll (1968) and Kettenring (1971).

Instead of analysing the contingency table (or cross-tabulation matrix), as CA does, MCA analyses an indicator matrix: a binary coding matrix of the factors, known as dummy variables. The rows are the total sample items and the columns are the total categories of the variables. It is an Individuals $x$ Variables matrix, where the rows represent individuals and the 
columns the categories of the variables. Analysis of the indicator matrix allows the representation of individuals as points in geometric space. Associations between variables are uncovered by calculating the Chi-Square metric distance between different modalities of the variables and between individuals. These associations are then represented graphically as "maps", which facilitate the interpretation of the structures in the data. Oppositions between row and column profiles are then maximised, in order to uncover the underlying dimensions the more able to describe the central oppositions in the data. As in Factor Analysis (FA) or PCA, the first axis is the most important dimension, the second axis the second most important, and so on. The number of axes to be retained for analysis is determined by calculating modified eigenvalues. Interpretation in MCA is based upon proximities between points in a low-dimensional map, that is to say two or three dimensions.

With this method, we will study the relations between the levels of comfort of the selected restaurants in Paris, the quality of their cooking and the practiced prices, in 1960 and in 2012 to compare the two situations.

\subsection{Results and discussion}

With regard to the Paris situation in 1960, the MCA gives a first eigenvalue (2.339) whose explanatory power is only $58.5 \%{ }^{14}$. We consider a search for a second eigenvalue (1.506) to be of interest, which explains $37.7 \%$ of the total variance. The eigenvalues graphic below (Appendix 2) shows that two dimensions appear clearly (the two eigenvalues higher than 1). Graphically, we will represent the situation of the statistical units through two modified eigenvalues (Figure 3). For each qualitative variable, the categories are placed in the centre of gravity of the units corresponding to it.

\footnotetext{
14 "MCA codes data by creating several binary columns for each variable with the constraint that one - and only one - of the columns gets the value 1 . This coding schema creates artificial additional dimensions because one categorical variable is coded with several columns. As a consequence, the inertia (i.e. variance) of the solution space is artificially inflated - and therefore the inertia percentage explained by the first dimension is severely underestimated." (Abdi and Valentin, 2007: 655).
} 


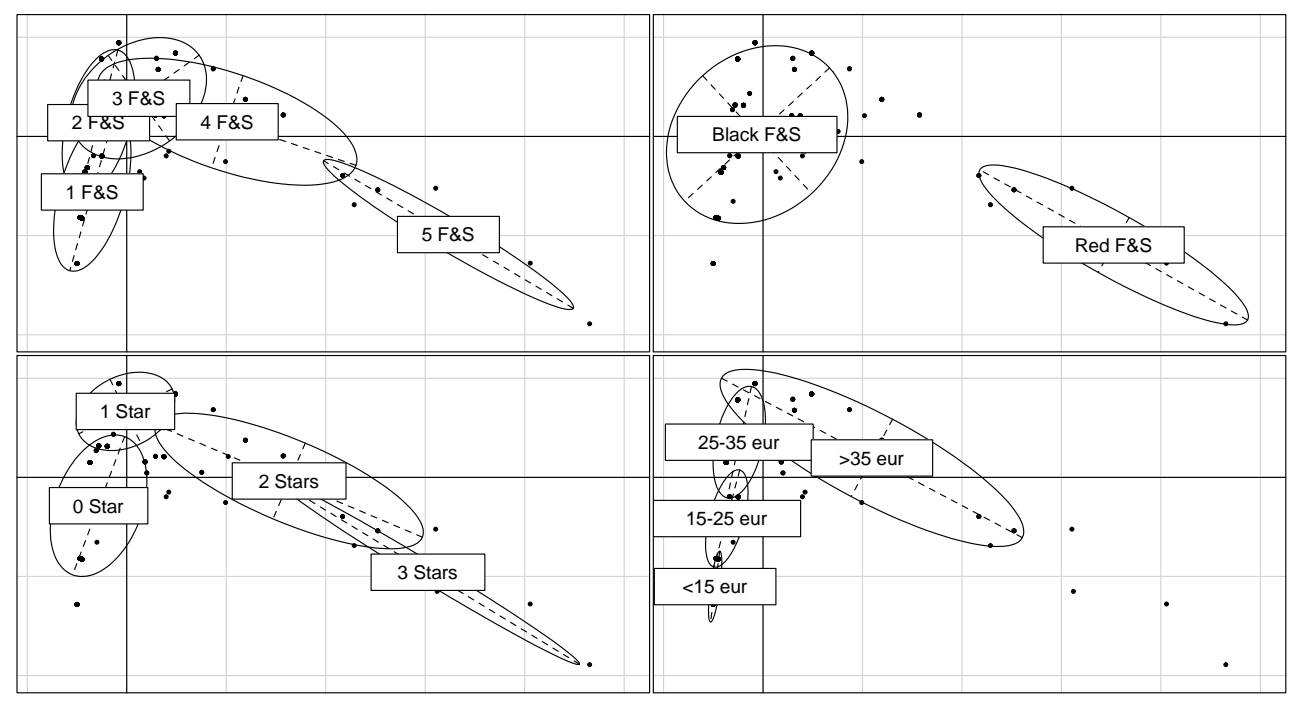

Figure 3. MCA of Parisian gastronomy in 1960 [Scatter Plot]

The bond is achieved through the position of the categories. We start by reading the correlation ratios of the synthesis variables with the original variables (Appendix 3 ) in order to focus the study on those variables which are more structuring. In this precise case, we can see that the comfort $(0.7033)$, the cooking $(0.6986)$ and the price $(0.5810)$ act on the first synthesis variable. For the second synthesis variable, we have price (0.5429), the cuisine (0.5173) and comfort level (0.3926). The first eigenvalue thus explains $70.3 \%$ of the comfort variable, $69.9 \%$ of the cuisine variable and $58.1 \%$ of the price variable. The second dimension of our analysis explains $54.3 \%$ of the price variable, $51.7 \%$ of the cuisine variable and $39.3 \%$ of the comfort variable.

Figure 3 shows three groups taking shape in the Parisian gastronomic landscape in 1960:

- Restaurants with 4 and 5 F\&S, 2 or 3 stars, the most pleasant settings (red F\&S) and the highest prices (above $€ 35$ ).

- $3 \mathrm{~F} \& S$ restaurants with one star, black F\&S and high prices (above $€ 35$, or between $€ 25$ and $€ 35)$. 
- 1 and 2 F\&S restaurants with no stars, black F\&S and the lowest prices (sub-€15 for the $1 \mathrm{~F} \& \mathrm{~S}$ establishments and between $€ 15$ and $€ 25$ for the $2 \mathrm{~F} \& S$ ).

With regard to the field of gastronomy in Paris in 2012, the first eigenvalue is 2.921, which explains $73.02 \%$ of total variance, and the second eigenvalue is 1.891 , explaining $47.26 \%$ of total variance (Appendix 5). Which means that on average, there is a relatively strong relationship between the synthesis variable and the original variables, relations that we are able to break down using the correlation ratios (Appendix 6) - respectively 0.86 (price), 0.81 (comfort), 0.80 (cuisine) and 0.45 (red F\&S) - with the first eigenvalue. The second eigenvalue explains $72 \%$ of the price variable, $63 \%$ of the comfort variable, $53 \%$ of the cooking variable and $1 \%$ of the red $\mathrm{F} \& \mathrm{~S}$ variable.

The category averages (centroid co-ordinates, Appendix 7) are, for example (for the first dimension) for the $5 F \& S$ group -3.96 , for the 3-star group -3.92 and -3.38 for the prices over- $€ 150$ group; and for the $1 F \& S$ group 0.41 , for the Bib group 0.54 and 0.46 for the prices $s u b-€ 50$ group. Thus we observe that typical profiles emerge from our statistical analysis. We offer a graphic representation encompassing all of these averages, in order to formally identify them. 

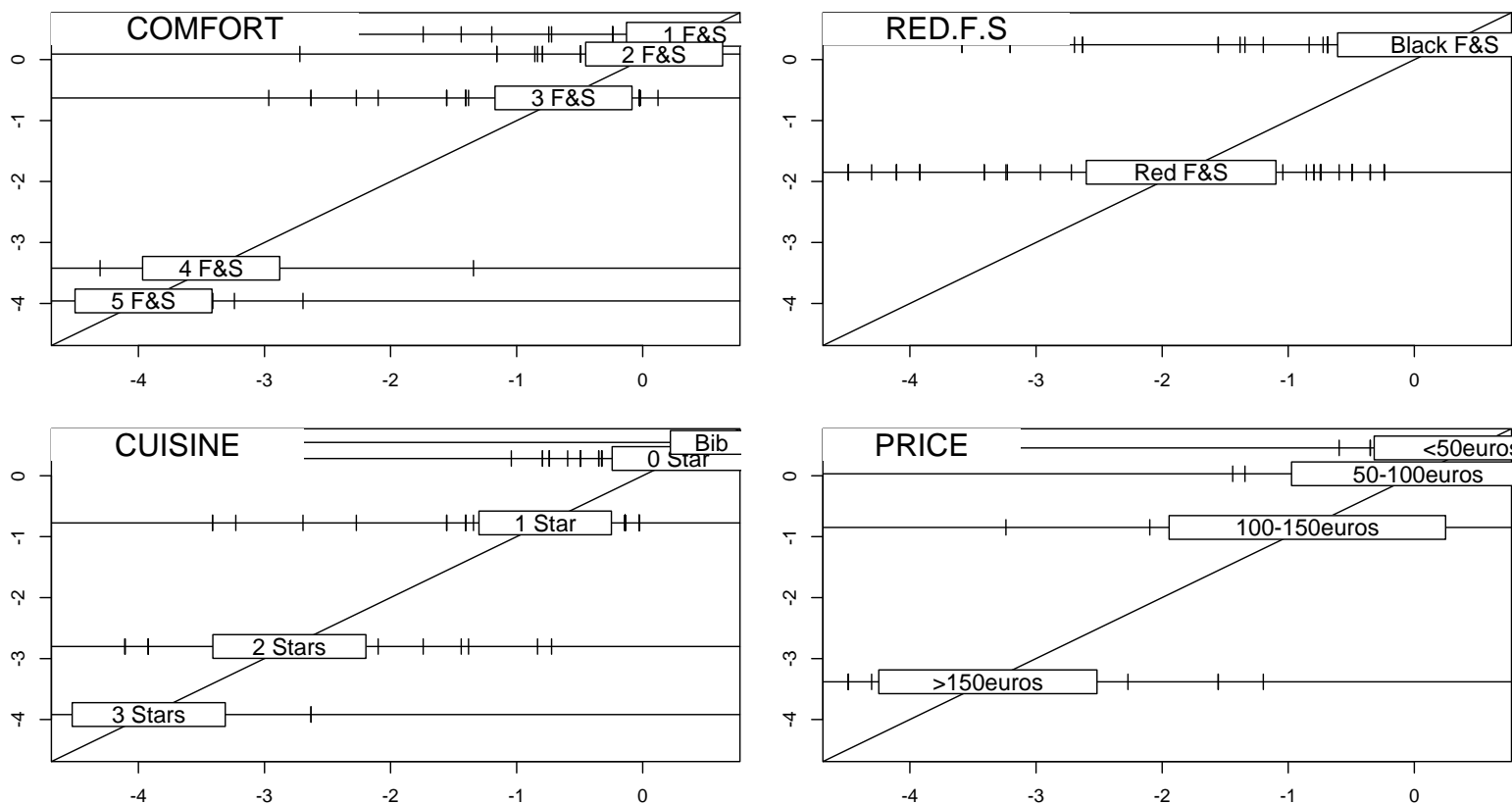

Figure 4. MCA of Parisian gastronomy in 2012 [Graphic Plot]

Each graph concerns one variable (Figure 4 and Figure 5). The top left graphic corresponds to the comfort variable. Each of the five horizontal lines represents one modality of the variable. On each line are features corresponding to the values taken by the synthesis variable, (for statistical units only), which belong to the category in question. The average of these values is calculated, and the square bearing the name of the category is positioned at the average point. The distance between, these mean squares indicates a strong correlation ratio between the synthesis variable and the variable considered, and therefore a strong connection. 


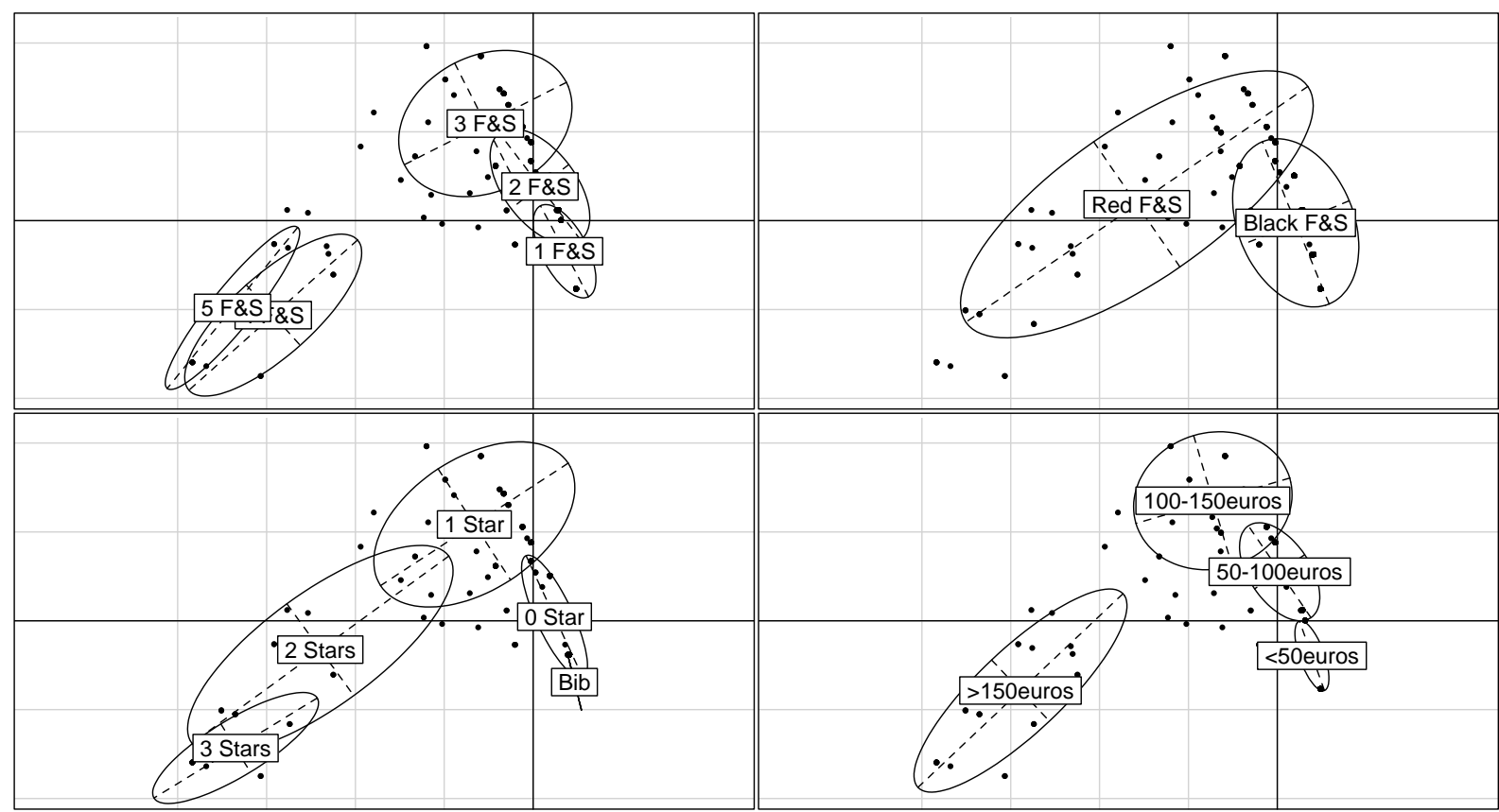

Figure 5. MCA of the Parisian gastronomy in 2012 [Scatter Plot]

For example, according to the graphic located on at top left: "Comfort", we see that the restaurants having $5 \mathrm{~F} \& \mathrm{~S}, 4 \mathrm{~F} \& \mathrm{~S}$ and $3 \mathrm{~F} \& \mathrm{~S}$ correspond to negative values on the synthesis variable. Conversely, those restaurants having $2 \mathrm{~F} \& S$ and $1 \mathrm{~F} \& S$ correspond to positive values on the synthesis variable. At the same time, the graphic at bottom left: "Cuisine", relating to the cuisine variable, shows that restaurants obtaining 3 stars, 2 stars and 1 star also have negative values. Inversely, those gastronomic establishments obtaining a Bib Gourmand or no stars have positive values on the plot. In parallel, the graphic at bottom right: "Price" shows that $s u b-€ 50$ and $€ 50$ - $€ 100$ are clustered on the positive side of the graphics and the $€ 100$ to $€ 150$, and over- $€ 150$ price categories are located on the negative side. Lastly, in the top right graphic plot: "Red $F \& S$ ", the black $F \& S$ category is on the positive side of the graphics whereas the red $F \& S$ category is on the negative side. We thus observe proximities between categories of variables, so that typical profiles emerge from our statistical analysis.

In short we note that four profiles arise here: 
- Restaurants with $4 F \& S$ and $5 F \& S, 2$ or 3 stars, the most pleasant settings (red F\&S) and the highest prices (over $€ 150$ ).

- 3 F\&S restaurants with 1 star and fairly high prices (between $€ 100$ and $€ 150$ ).

- $2 F \& S$ restaurants with no awards, black F\&S and charging between $€ 50$ and $€ 100$.

- The $1 F \& S$ restaurants have Bib Gourmand, black F\&S and the lowest prices (sub €50).

To complete our analysis we ran an MCA on Parisian gastronomy in 2010 including the study of few others variables (See 5.1 Empirical specification and data: 13). We obtain a first dimension with a synthesis capacity of 0.3003 . The fall of the eigenvalues (Appendix 8) shows here that two dimensions arise for an explanatory power of $66.9 \%$, and the following graph provides us with more detailed profiles of the Parisian restaurants.

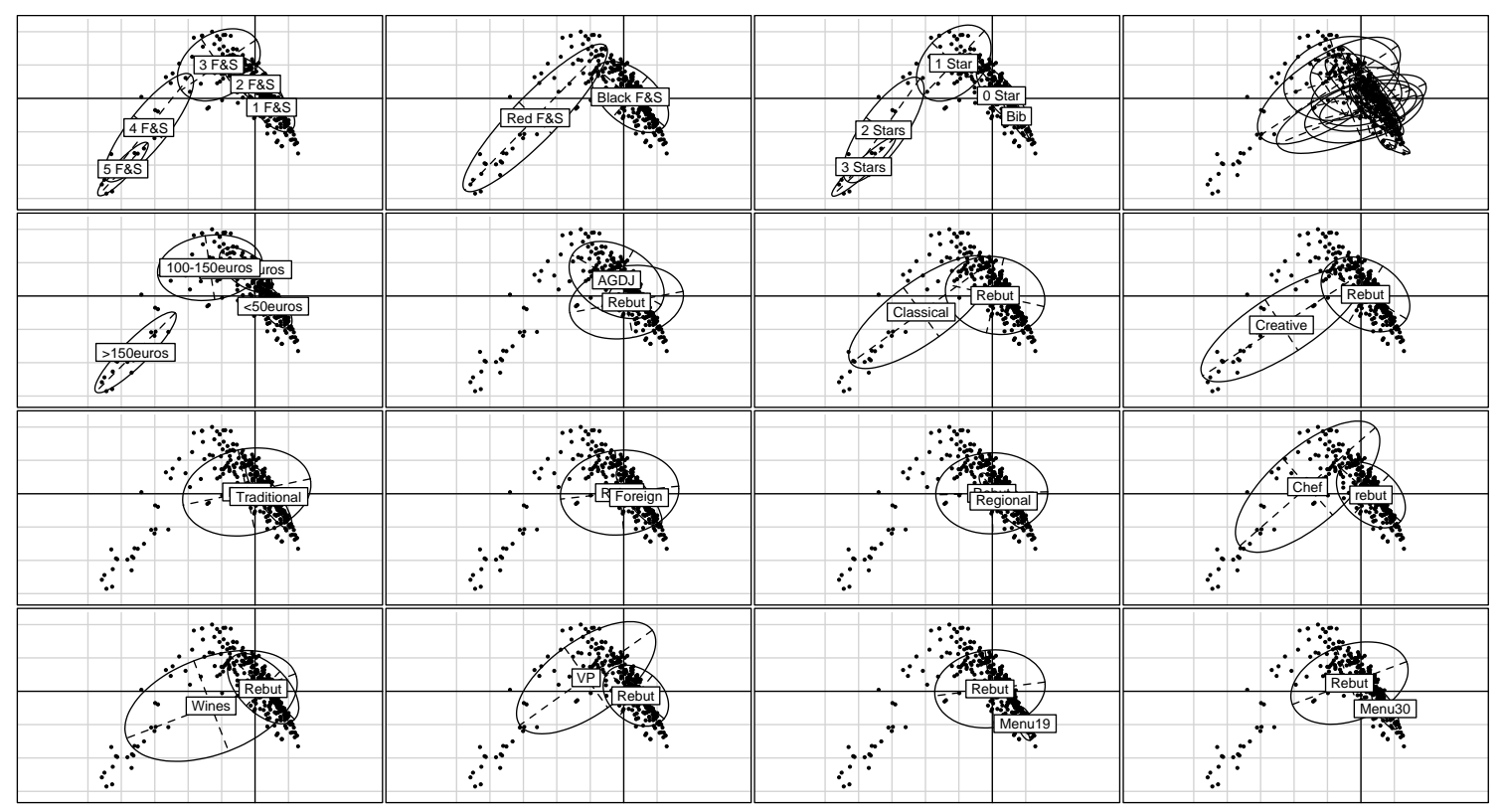

Figure 6. Refined MCA of Parisian gastronomy in 2010

Establishments having 4-5 F\&S, have red F\&S, 2-3 stars and prices over $€ 150$. These restaurants serve a traditional or creative cuisine, have a well-reputed chef, offer a distinctive wine list and provide valet parking. Restaurants with $3 \mathrm{~F} \& \mathrm{~S}$ have one star and prices of 
between $€ 100$ and $€ 150$. They serve a traditional, creative or "Au goût $d u$ jour" cuisine, have a famous chef, offer a distinctive wine list and valet parking. These "starred" restaurants are localised in such beautiful and tourist districts of Paris as the $8^{\text {th }}, 16^{\text {th }}, 6^{\text {th }}, 7^{\text {th }}, 17^{\text {th }}$ and $1^{\text {st }}$ arrondissements. Establishments having $2 \mathrm{~F} \& S$ have black F\&S, no stars and prices between $€ 50$ and $€ 100$. They supply "Au goût du jour" cuisine. Establishments having 1 F\&S have black F\&S, Bib Gourmand and sub-€50 prices. They offer traditional French, regional or foreign cuisine. They also offer sub- $€ 30$ or sub- $€ 19$ fixed-price menus. They are located in the more ordinary districts of the capital, in the $11^{\text {th }}, 14^{\text {th }}, 15^{\text {th }}, 3^{\text {rd }}, 9^{\text {th }}$, and $18^{\text {th }}$ arrondissements.

In 1960, then, Parisian gastronomy was segmented into three profiles (the 4-5 F\&S with 2-3 stars, the most pleasant settings, and the highest prices; the $3 F \& S$ with one star and midpriced-to high prices, and the 1-2 F\&S, without any awards, and with the lowest prices). However, it would seem that the situation of the French capital had changed by 2010 - 2012, since at this point, we can identify four profiles among Michelin selections (the 4-5 F\&S with 2-3 stars, the most pleasant settings, and the highest prices; the $3 F \& S$ with 1 star and relatively high prices, the $2 F \& S$ unadorned with gastronomic awards, and the $1 F \& S$, with Bib Gourmand and the lowest prices). Segmentation in Parisian gastronomy has thus been altered by the appearance of a new low-cost category, which is playing an active role in the "democratisation" and the "mass-consumption" of French Grande Cuisine, confirming the significance of the 1990s turning point.

\section{Concluding remarks: From a turning point to the limits of the}

\section{elitist gastronomy}

The three clearly-identified segments of 1960 have now become four. The rise in the number of establishments in the lowest categories of comfort and quality, the fall in the average quality of the setting, and the development of lower-quality levels such as Bib Gourmands seem to testify to a change in the definition and legitimation of gastronomic suppliers. This 
does not mean that exceptional gastronomy (3 Michelin stars) has disappeared, but rather that various kinds of gastronomy cohabit across the Parisian landscape. In order to confirm these hypotheses, new analyses need to be undertaken. One question concerns the scope of the observed changes; is this just a French specificity?

Initial recent results suggest that changes in the gastronomic field are not limited to the Parisian area. For instance, it is also the case in New York, where in 2011 the Michelin guidebook has selected 715 restaurants. 57 of these are starred (as against 70 in Paris). The segments $0+1 F \& S$ and $2+3 F \& S$ represent, respectively, $50.3 \%$ and $48 \%$ of the New York selected establishments. The luxury segment $(4+5 F \& S)$ represents just $1.7 \%$. These figures mean that New York cuisine is very "democratic", perhaps much more so than its Parisian counterpart. In New York there are many "simple comfort" restaurants $(O F \& S)$. Michelin has also created a new award: "Small Plates" (Restaurants in this category offer a single menu, ambiance and service). According to Michelin: "This category includes a completely new selection of establishments with a unique style of menu, ambiance and service not previously included in any Michelin Guide. This category was added to reflect the increasing popularity and quality of establishments with this style". It exists only in the two US Michelin Guides (New York City and San Francisco). The emergence of this category reflects the growing popularity of such restaurants, which provide gastronomic quality at reasonable prices, and tends to illustrate the "massification" of the gastronomic field. The same is true of Tokyo. Since 2011, Michelin Guide Tokyo has had a new pictogram : ${ }^{0}$. It indicates a starred restaurant offering a sub- 5,000 yen menu for lunch and/or diner. According to Michelin: "Value for money is one of five criteria to select star restaurants, and the new pictogram serves readers to find local eateries at affordable prices". Thus, the elitist restaurant is no longer the unique dominant model, as a kind of gastronomic pluralism develops and a new category of restaurant emerges: extraordinary ways of cooking are no longer the exclusive 
symbol of luxury and taste. In other words, creativity using ordinary foodstuffs and settings attracts a wider, less wealthy clientele, looking for new codes such as pure, healthy products, less sophisticated settings and so on.

Another issue is the interpretation of the apparent crisis in elitist gastronomy. Different reasons must be analysed and tested. Elitist gastronomy is founded on the reputation of the grand chef, which is difficult to reproduce when he disappears. A strong rise in costs derives from a Baumol effect (Baumol and Bowen, 1966): production costs rise higher and higher, and it is impossible to achieve productivity gains (for cuisine and restaurant staff, for instance). Gastronomic restaurants can therefore only subsist where their customers are numerous and rich. The evolution of tastes and preferences constitutes another hypothesis. Sophistication is questioned by the vogue for nature and natural products. For instance, vegetables used to be considered in France as ordinary food - yet today, they have become the basis of highly-valued dishes. Ecological values are opposed to waste, and this has an influence on cooking - as shown by the Slow Food movement. Lastly, the globalisation process mixes cultures and heritages. Culinary heritages can be used outside of their original area, products, sauces, spices and way of cooking are at everyone's disposal everywhere, and transport costs are falling. Consumers are interested in new experiments; they actively seek out new culinary heritages. Multiculturalism is growing, and world fusion cuisine is spreading. The elitist French heritage gave competitive advantages but because it is strongly encapsulated in a specific culture, and linked to a specific history, its rigidity hampers adaptation to cultural changes; lock-in phenomena are developing. At the same time, although they belong to a world of shared gastronomic resources, diverse cuisines are in competition with one another. Some, more flexible, are capable of fast adaptation; new styles appear and challenge the old hierarchy. Newly-gastronomic countries, namely Spain, Germany and 
England - are calling French supremacy into question ${ }^{15}$. The reach of "democratisation" then, extends far beyond the French capital, and seems to be international. Conversely the Old French model of gastronomy, based on the leading role of the Grand restaurant can no longer pretend to control world gastronomy. For gastronomy, it really is true that "The Times They Are a-Changin".

\footnotetext{
${ }^{15}$ In 2011, although French cuisine is often considered as the best in the world, The World's 50 Best Restaurant Awards (http://www.theworlds50best.com/awards/1-50-winners) gave a ranking of the best chefs putting 9 chefs from Denmark, Spain, Italy, Brazil and England before the first French one, Inaki Aizpitarte. At the same time, after the UNESCO featured "gastronomic meal of the French" on its list of the world's intangible heritage, some gastronomic experts published books and papers dealing with the decline or even the death of French cuisine.
} 


\section{References}

Abdi, Hervé and Dominique Valentin (2007). Multiple Correspondence Analysis. In Salkind N. J. (Editions), Encyclopedia of Measurement and Statistics, Thousand Oaks, Sage: 651657.

Baumol, William J. and William G. Bowen (1966). Performing Arts - The Economic Dilemma: A Study of Problems Common to Theater, Opera, Music and Dance. Cambridge: MIT Press.

Benzécri, Jean-Paul (1973). L'Analyse des Données. Tome 1: La Taxinomie. Tome 2: L'Analyse des Correspondances. Paris: Dunod.

Burt, Cyril (1950). The factorial analysis of qualitative data, British Journal of Mathematical and Statistical Psychology. 3: 166-185.

Carroll, J. Douglas (1968). Generalization of canonical correlation to three or more sets of variables, American Psychiatric Association. 3: 227-228.

Escoffier-Cordier, Brigitte (1965). L'Analyse des correspondances. Thèse pour le doctorat de sciences, Université de Rennes, France. Publiée dans les Cahiers du Bureau Universitaire de Recherche Opérationnelle, $1969, \mathrm{n}^{\circ} 13$.

Guttman, Louis (1941). The quantification of a class of attributes: a theory and method of scale construction, in: Committee on Social Adjustment Editions, The Prediction of Personal Adjustment. New York: Social Science Council: 319-348.

Hayashi, Chikio (1956). Theory and examples of quantification, Proceedings of the Institute of Statistical Mathematics. 4: 19-30.

Horst, Paul (1961). Relation among m sets of measures, Psychometrika. 26: 129-149.

Kettenring, John R. (1971). Canonical analysis of several sets of variables, Biometrika. 58: 433-450. 
Masson, Michel (1974). Analyse non linéaire de données, Comptes Rendues de l'Académie des Sciences. 287: 803-806. 
Appendices

Appendix 1. Pearson's Chi-Square Test (Paris 1960)

\begin{tabular}{|c|c|c|c|c|c|}
\hline & & COMFORT & RED.F\&S & CUISINE & PRICE \\
\hline \multirow[t]{3}{*}{ COMFORT } & Pearson's Correlation & 1 & .528 & $.559^{x *}$ & .741 \\
\hline & Sig. (bilateral) & & .000 & .000 & .000 \\
\hline & $\mathrm{N}$ & 661 & 661 & 661 & 661 \\
\hline \multirow[t]{3}{*}{ RED.F\&S } & Pearson's Correlation & $.528^{\pi \pi}$ & 1 & $.437^{* \pi}$ & $.542^{\pi x}$ \\
\hline & Sig. (bilateral) & .000 & & .001 & .000 \\
\hline & $\mathrm{N}$ & 661 & 661 & 661 & 661 \\
\hline \multirow[t]{3}{*}{ CUISINE } & Pearson's Correlation & $.559^{\pi x}$ & $.437^{* \pi}$ & 1 & $.638^{\pi \pi}$ \\
\hline & Sig. (bilateral) & .000 & .001 & & .000 \\
\hline & $\mathrm{N}$ & 661 & 661 & 661 & 661 \\
\hline \multirow[t]{3}{*}{ PRICE } & Pearson's Correlation & $.741^{\pi x}$ & $.542^{\pi \pi}$ & $.638^{\star \pi}$ & 1 \\
\hline & Sig. (bilateral) & .000 & .000 & .000 & \\
\hline & $\mathrm{N}$ & 661 & 661 & 661 & 661 \\
\hline
\end{tabular}

**. The correlation is significant at 0.01 (bilateral).

\section{Appendix 2. Eigenvalues of MCA (Paris 1960)}

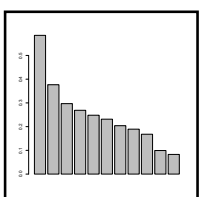

Appendix 3. Correlation Ratio of Synthesis Variables with Original Variables (Paris 1960)

\begin{tabular}{l|cc} 
Correlation & RS1 & RS2 \\
\hline Comfort & 0.7033 & 0.3926 \\
Red.F\&S & 0.3557 & 0.0533 \\
Cuisine & 0.6986 & 0.5173 \\
Price & 0.5810 & 0.5429
\end{tabular}

Appendix 4. Pearson's Chi-Square Test (Paris 2012)

\begin{tabular}{|ll|c|c|c|c|}
\hline & & & & \\
& & COMFORT & RED.F\&S & CUISINE & PRICE \\
\hline COMFORT Pearson's Correlation & 1 & $.458^{\star \star}$ & $.531^{\star \star}$ & $.740^{\star \star}$ \\
& Sig. (bilateral) & & .000 & .000 & .000 \\
& $\mathrm{~N}$ & 456 & 456 & 456 & 456 \\
\hline RED.F\&S & Pearson's Correlation & $.458^{\star \star}$ & 1 & $.363^{\star \star}$ & $.476^{\star \star}$ \\
& Sig. (bilateral) & .000 & & .000 & .000 \\
& $\mathrm{~N}$ & 456 & 456 & 456 & 456 \\
\hline CUISINE & Pearson's Correlation & $.531^{\star \star}$ & $.363^{\star \star}$ & 1 & $.636^{\star \star}$ \\
& Sig. (bilateral) & .000 & .000 & & .000 \\
& $\mathrm{~N}$ & 456 & 456 & 456 & 456 \\
\hline PRICE & Pearson's Correlation & $.740^{\star \star}$ & $.476^{\star *}$ & $.636^{\star *}$ & 1 \\
& Sig. (bilateral) & .000 & .000 & .000 & \\
& $\mathrm{~N}$ & 456 & 456 & 456 & 456 \\
\hline
\end{tabular}

**. The correlation is significant at 0.01 (bilateral).
Appendix 5. Eigenvalues of MCA (Paris 2012)

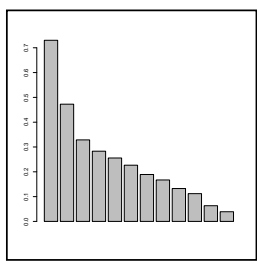

Appendix 6. Correlation Ratio of Synthesis Variables with Original Variables (Paris 2012)

\begin{tabular}{l|c|c} 
Correlation & RS1 & RS2 \\
\hline Comfort & 0.813 & 0.632 \\
Red.F\&S & 0.450 & 0.009 \\
Cuisine & 0.795 & 0.534 \\
Price & 0.863 & 0.715
\end{tabular}

Appendix 7. Coordinates of the Centroids (Paris 2012)

\begin{tabular}{|l|l|l|}
\hline & Comp1 & Comp2 \\
\hline COMFORT.1.F.S & 0.41429737 & -0.49974312 \\
COMFORT.2.F.S & 0.09078387 & 0.55923906 \\
COMFORT.3.F.S & -0.62882713 & 1.59046335 \\
COMFORT.4.F.S & -3.42283373 & -1.54605662 \\
COMFORT.5.F.S & -3.95956313 & -1.42756415 \\
\hline RED.F.S.Black.F.S & 0.24323709 & -0.03522689 \\
RED.F.S.Red.F.S & -1.84951974 & 0.26785730 \\
\hline CUISINE.0.Star & 0.28253505 & 0.06523984 \\
CUISINE.Bib & 0.54567041 & -1.00297353 \\
CUISINE.1.Star & -0.77357995 & 1.57837000 \\
CUISINE.2.Stars & -2.80226069 & -0.47303943 \\
CUISINE.3.Stars & -3.91828311 & -2.08277918 \\
\hline PRICE..50euros & 0.45648713 & -0.57303480 \\
PRICE.50.100euros & 0.03182216 & 0.80277363 \\
PRICE.100.150euros & -0.84829991 & 1.96542911 \\
PRICE..150euros & -3.38168758 & -1.14200737 \\
\hline
\end{tabular}

Appendix 8. Eigenvalues of MCA (Paris 2010 refined)

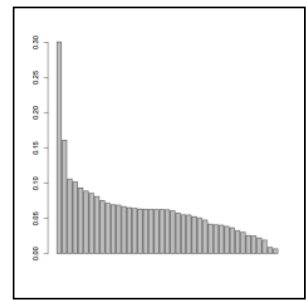

